\title{
Assessment of intraatrial lateral tunnel anatomy and venous blood flow in children with hypoplastic left heart syndrome in Fontan circulation
}

\author{
Inga Voges ${ }^{1 *}$, Michael Jerosch-Herold ${ }^{2}$, Jens Scheewe ${ }^{1}$, Christopher Hart ${ }^{1}$, Dominik Daniel Gabbert ${ }^{1}$, \\ Traudel Hansen ${ }^{1}$, Hans-Heiner Kramer $^{1}$, Carsten Rickers ${ }^{1}$
}

From 15th Annual SCMR Scientific Sessions

Orlando, FL, USA. 2-5 February 2012

\section{Background}

In patients (pts) with hypoplastic left heart syndrome (HLHS) post completion of the total cavopulmonary connection (TCPC) with an intraatrial lateral tunnel, deviations of the tunnel from an ideal tubular shape are common. However, little is known about frequency and potential adverse effects of such shape deviations. Therefore, we sought to analyze intraatrial lateral tunnel anatomy, dimensions and blood flow in children with HLHS with cardiac magnetic resonance imaging (CMR).

\section{Methods}

Sixty-one pts with HLHS (mean age, $6.4 \pm 2.7$ years, range, 3.2-14 years) underwent 3.0-T CMR (Achieva 3.0T, Philips Medical Systems) with gradient-echo cine sequences $(\mathrm{FOV}=280 \times 224 \mathrm{~mm}, \mathrm{TR} / \mathrm{TE}=4.4 / 2.5 \mathrm{~ms}), 2 \mathrm{D}$ phase-contrast cine imaging $(\mathrm{FOV}=270 \times 270 \mathrm{~mm}, \mathrm{TR} /$ $\mathrm{TE}=4.4 / 2.7 \mathrm{~ms}, \mathrm{VENC}=100 \mathrm{~cm} / \mathrm{s}$ ) and flow-sensitive 3D-phase-contrast CMR (FOV $=320 \mathrm{~mm}, \mathrm{TR} / \mathrm{TE}=3.3 / 2.2$ $\mathrm{ms}, 12$ slices, 25 phases). We analyzed tunnel anatomy, diameters, cross-sectional areas and volumes of the tunnel. Tunnel blood flow was measured at the level below the connection of the inferior vena cava with the pulmonary arteries.

\section{Results}

23 pts had a tubular-shaped tunnel (Figure 1). In 28 pts bulging and/or narrowing at different locations of the

'Department of Congenital Heart Disease and Pediatric Cardiology,

University Hospital of Schleswig-Holstein, Kiel, Germany

Full list of author information is available at the end of the article tunnel was present (Figure 1) (2-4). In 10 pts a classification was not possible because of susceptibility artifacts from implanted devices. Cross-sectional areas, volume of the tunnel, the mean blood flow and the mean and maximal flow velocity were not significant different between pts with a tubular tunnel and pts with shape deviations of the tunnel. In all pts we found a relation between the normalized tunnel volume and age $(r=0.44$; $\mathrm{p}=0.002)$, body surface area $(\mathrm{r}=0.42 ; \mathrm{p}=0.005)$ and time after TCPC $(\mathrm{r}=0.42 ; \mathrm{p}=0.001)$. The mean tunnel blood flow correlated with age $(\mathrm{r}=0.75 ; \mathrm{p}=0.001)$ and body surface area $(r=0.83 ; \mathrm{p}<1.0 \mathrm{e}-4)$. Flow-sensitive 3D-phasecontrast CMR showed retrograde flow at the junction between the inferior vena cava and the intraatrial tunnel as well as a non-linear tunnel blood flow (e.g. reflux, vortices) below the fenestration.

\section{Conclusions}

1) The volume and the mean blood flow of the intraatrial lateral tunnel correlated with age and body surface area of HLHS pts in Fontan circulation, suggesting that the conduit capacity of the tunnel adjusts to body growth, unlike an extracardiac tube. 2) Flow-sensitive 3D phase-contrast CMR showed a non-linear blood flow in the lower part of the tunnel. Follow-up CMRs are needed to detect long term effects of irregular tunnel shapes on flow dynamics.

\section{Funding}

This study was supported by the Deutsche Gesellschaft für Pädiatrische Kardiologie (http://www.kinderkardiologie.org, Achenbachstr. 43, 40237 Düsseldorf, Germany). 

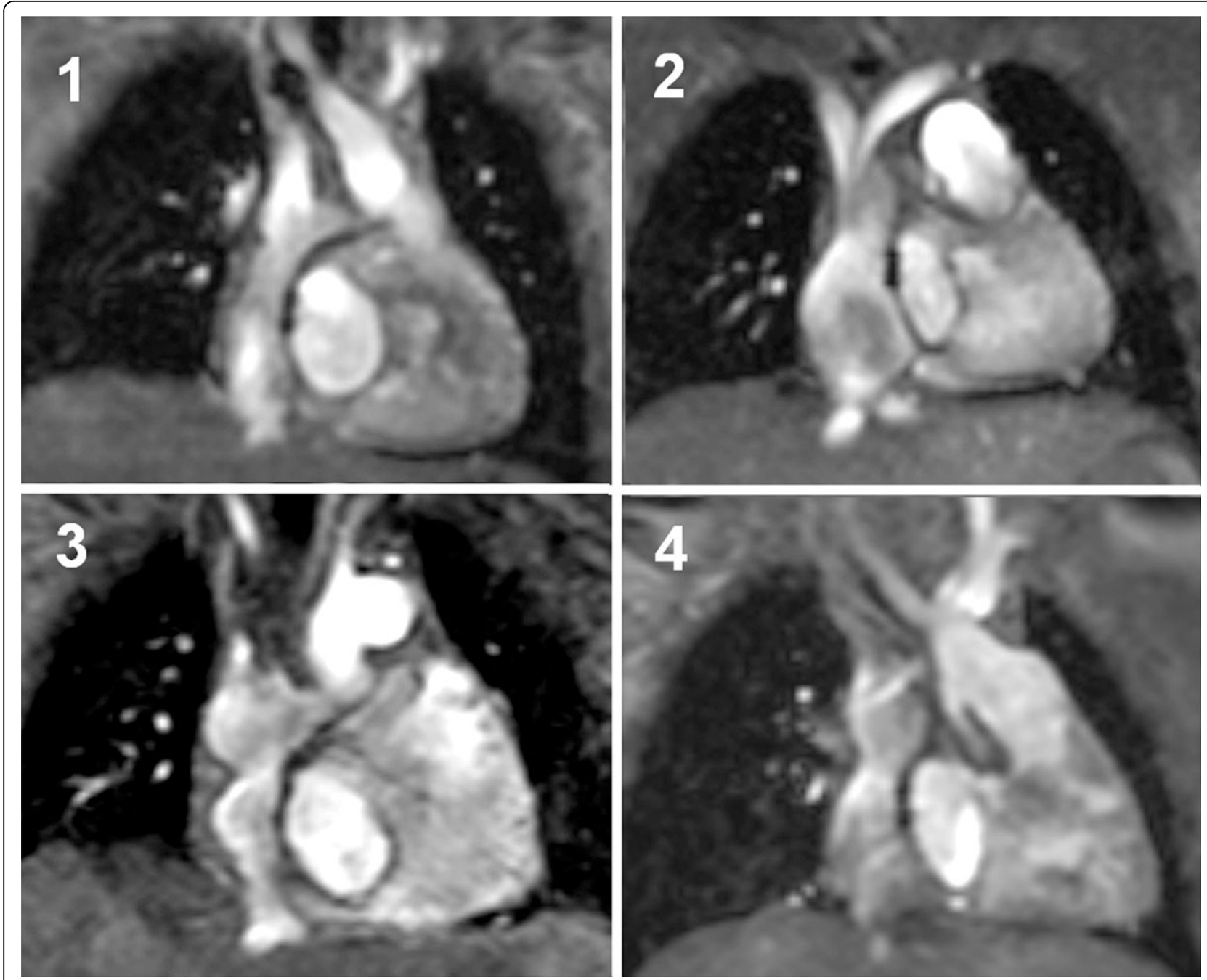

Figure 1

\section{Author details}

${ }^{1}$ Department of Congenital Heart Disease and Pediatric Cardiology,

University Hospital of Schleswig-Holstein, Kiel, Germany. ${ }^{2}$ Department of

Radiology, Brigham \& Women's Hospital \& Harvard Medical School, Boston, MA, USA.

Published: 1 February 2012

doi:10.1186/1532-429X-14-S1-P113

Cite this article as: Voges et al:: Assessment of intraatrial lateral tunnel anatomy and venous blood flow in children with hypoplastic left heart syndrome in Fontan circulation. Journal of Cardiovascular Magnetic Resonance 2012 14(Suppl 1):P113.

\section{Submit your next manuscript to BioMed Central} and take full advantage of:

- Convenient online submission

- Thorough peer review

- No space constraints or color figure charges

- Immediate publication on acceptance

- Inclusion in PubMed, CAS, Scopus and Google Scholar

- Research which is freely available for redistribution

Submit your manuscript at www.biomedcentral.com/submit 